\title{
REFLEXÕES NA GEOGRAFIA CULTURAL: A MATERIALIDADE E A IMATERIALIDADE DA
} CULTURA

\section{Reflections on Cultural Geography: the Materiality and Immateriality of the Culture}

\author{
Jessica Nene Caetano \\ Mestranda do Programa de Pós-Graduação em Geografia e Geociências, UFSM \\ Universitária/RS - Brasil \\ sicaetano@yahoo.com.br \\ Meri Lourdes Bezzi \\ Professora Doutora, Depto. de Geociências, UFSM. \\ Universitária/RS - Brasil \\ meribezzi@yahoo.com.br
}

Artigo recebido em 18/07/2011 e aceito para publicação em 29/11/2011.

RESUMO: O presente artigo visa contribuir teoricamente com o estudo da Geografia Cultural, uma vez que esta é uma tendência da ciência geográfica centrada no conceito de cultura, alicerçada por conceitos basilares, entre eles, o de paisagem cultural e código cultural. Desse modo, pretende-se relacionar os referidos conceitos, compreendendo que a paisagem cultural é o resultado do sistema simbólico de um grupo cultural formado por códigos culturais materiais e imateriais representativos.

Palavras-chave: Cultura. Paisagem Cultural. Códigos Culturais.

ABSTRACT: This article aims to contribute theoretically to the study of cultural geography, since this is a trend of geographic science centered on the concept of culture, underpinned by basic concepts, including the cultural landscape and cultural codes. Thus seek to link these concepts, understanding the cultural landscape is the result of the symbolic system of a cultural group made up of material and immaterial cultural codes representative.

Keywords: Culture. Cultural Landscape. Cultural Codes. 


\section{INTRODUÇÃO}

A Geografia Cultural, uma tendência da ciência geográfica, passou por transformações teóricas no decorrer de sua evolução. A centralidade para a materialidade da cultura, ou seja, a ênfase para os elementos visíveis na paisagem promovida por Carl Sauer $(1889 ; 1975)$ foi superada pela união entre o material e o imaterial presente no sistema simbólico de determinado grupo cultural afirmado por Paul Vidal de La Blache (1845; 1918).

Neste sentido, o trabalho resulta de reflexões sobre a temática cultural enfatizando os conceitos de paisagem e códigos culturais, relacionando-os como integrantes de uma mesma perspectiva de estudo, ou seja, não existe paisagem cultural sem códigos culturais e vice-versa, pois os mesmos manifestam-se na paisagem, demonstrando as peculiaridades espaciais que o homem, mediado pelos artefatos técnicos, materializa nas paisagens tornando-as singulares.

O presente artigo desenvolve, primeiramente, o estudo sobre o conceito de paisagem cultural e sua evolução na Geografia para, posteriormente, apresentar os principais aspectos vinculados aos códigos culturais e sua manifestação na paisagem resultando na paisagem cultural.

Por conseguinte, a pesquisa constitui-se em uma reflexão teórica visando fornecer subsídios para discussões conceituais com o objetivo de enriquecer os estudos atrelados à Geografia Cultural brasileira. Ressalta-se a importância dessa tendência para a inserção de um novo "olhar" geográfico para a cultura, enfatizando que a evolução da mesma se fez através da contribuição das demais ciências sociais, como a Antropologia, a História e a Sociologia com as quais a Geografia busca dialogar.

\section{A FORMAÇÃO DA PAISAGEM CULTURAL}

A temática da paisagem é resgatada pelos geógrafos ao possibilitar os estudos de sua morfologia a partir da década de 1960, baseados pelas contribuições teóricas de muitos autores, em especial, de Sauer. A paisagem, como objeto de interpretação da Geografia, permite a leitura da cultura e da história de um povo através da manifestação dos valores, crenças e demais atributos que os identificam. No entanto, segundo Mikesell (2000, p. 91) “A palavra paisagem, mesmo com seus significados múltiplos e ambíguos, não possui um sentido amplo e suficiente para se tornar sinônimo de geografia cultural".

Com esse propósito, Wagner; Mikesell (2007, p. 36) ressaltam que

O estudo da paisagem cultural serve, simultânea e inseparavelmente, a diversos fins diferentes. Independente da sua função de descrição sistemática proporciona uma base para classificação regional, possibilita um insight sobre o papel do homem nas transformações geográficas e esclarece certos aspectos da cultura e de comunidades culturais em si mesmas. Busca diferenças na paisagem que possam ser atribuídas a diferenças de conduta humana sob diferentes culturas e procura desvios de condições "naturais" esperadas, causados pelo homem.

A paisagem intocada pelo homem é formada, apenas, pelos elementos naturais e passa a receber a "marca" humana quando os grupos sociais desenvolvem técnicas que alteram esse meio natural. Assim, se faz necessária a integração do conhecimento físico-biológico ao se desenvolver um estudo atrelado ao processo de transformação da paisagem e a consequente repercussão dessas mudanças para os grupos culturais. Nessa linha de raciocínio, Leite (1994, p.13) afirma que

A partir do momento em que o homem trocou a atividade nômade por uma atividade localizada, passando de caçador a agricultor e criador, surgiu a primeira ligação estável entre ele e o espaço que o circundava. Essa mudança de atividade, ao mesmo tempo em que permitiu o desenvolvimento da produção para a sobrevivência, introduziu uma nova e profundamente importante alteração na relação do homem com a natureza: a possibilidade de transformar o cenário natural em um cenário construído, uma paisagem artificial, na qual as condições de sobrevivência são asseguradas pela repetição ativa dos ciclos observados na natureza. A aquisição de conhecimentos biológicos e a faculdade de organização dos processos bióticos, necessárias ao 
desenvolvimento das atividades sedentárias, surgem como características dominantes da nova estrutura ambiental.

Para Claval (2004, p.14) os diferentes termos referentes à paisagem têm origem do

\section{[...] alemão que forja o termo Landschaft,} e o inglês, landscape, para traduzir o novo termo holandês, cujo emprego se impõe com a difusão do novo gênero pictural. O italiano transcreve a ideia de extensão de pays, que vem da raiz land, criando paesaggio, de onde deriva o termo francês. Seu emprego é verificado a partir de 1549.

$\mathrm{O}$ autor enfatiza a possibilidade da paisagem ser interpretada como uma pintura que retrata uma porção da natureza escolhida pelo observador, evidenciando, a subjetividade inerente à representação dessa categoria do espaço como expressão fiel da realidade.

Nessa perspectiva, Claval, (2004, p.15) salienta que

Rapidamente se impôs a maneira de considerar a paisagem como qualquer "parte de pays que a natureza apresenta a um observador" (Petit Robert). Neste sentido amplo, desaparece a idéia de enquadramento da vista: o observador pode elevar ou abaixar seu olhar, virar sua cabeça, dar alguns passos, contornar um obstáculo. O destaque se transfere da perspectiva e do enquadramento observados para a parte do pays do qual se discerne a fisionomia.

Pode-se afirmar que muitas paisagens diferenciadas se formam a partir da existência de culturas com sistemas simbólicos representativos, que imprimem nesse espaço suas características peculiares. Assim, a paisagem ganha significado cultural, ou seja, as paisagens naturais "evoluem" para paisagens culturais. Resgata-se novamente Wagner; Mikesell (2007, p. 35) quando os autores apontam que
[...] A associação típica de características geográficas concretas numa região ou em qualquer outra subdivisão espacial da superficie terrestre pode ser descrita como uma "paisagem". Este termo abrange tanto as características distintas que servem para diferenciar uma região, como as características que não se limitam a uma região determinada, mas ocorrem nela. Então, a paisagem cultural refere-se ao conteúdo geográfico de uma determinada área ou a um complexo geográfico de certo tipo, no qual são manifestas as escolhas feitas e as mudanças realizadas pelos homens enquanto membros de uma comunidade cultural.

É importante resgatar que a paisagem tem-se constituído, ao longo da historiografia do pensamento geográfico, em uma das categorias analíticas para a interpretação espacial. Considerando-se que, inicialmente, as pesquisas geográficas eram baseadas na observação e descrição, as paisagens, principalmente, as agrárias, eram valorizadas pelos primeiros investigadores desse campo científico demonstrando que a presença do homem era fundamental na organização das mesmas. Gandy (2004, p. 74) destaca

A paisagem é um dos temas recorrentes do pensamento geográfico. No século XVIII, geógrafos como Humboldt e Ritter concebiam a paisagem como a interação da natureza (física) e da cultura. Tal concepção revela o aparecimento de uma preocupação com a classificação e o ordenamento da natureza, mas sugere também a consideração sobre a existência de laços materiais entre determinados tipos de sociedades e determinados tipos de paisagens. Nas últimas décadas do século XIX e na primeira metade do século XX, essa associação da paisagem e da cultura foi, em inúmeros casos, radicalmente reexaminada. Isso deu lugar a concepções baseadas em discursos ambientais deterministas, até mesmo reacionários. 
A paisagem, como categoria de análise da Geografia, ofereceu vasto espaço para o estudo dos elementos da natureza e da cultura. Wagner; Mikesell (2007, p. 45) enfatizam

O conhecimento dos efeitos da ação humana pode ser de valor prático: beneficia a humanidade saber o que ela faz ao mundo. Para identificar e descrever quaisquer dos processos que ajudaram a criar uma paisagem, especialmente aqueles processos nos quais a interferência humana está envolvida, deve ser conhecida a seqüência de condições antecedentes.

Esse contraste entre paisagem natural e paisagem humanizada foi elemento central de discussão científica na Alemanha, que criou como já referido anteriormente, o termo "landschaft" para agregar tanto as feições físicas da natureza quanto a ação humana sobre a mesma. A este respeito Sauer (2007, p. 22) afirma

Nunca se produziu, no entanto, nenhuma tentativa séria de eliminar as atividades do homem do estudo geográfico. Os alemães têm repetido durante muito tempo, uma frase: " a transformação da paisagem natural em paisagem cultural"; expressão que proporciona um programa de trabalho satisfatório no qual o conjunto das formas culturais em uma área merece a mesma atenção que o das formas fisicas. Toda a geografia é, com propriedade e segundo este ponto de vista, geografia fisica, não porque o trabalho humano esteja condicionado pelo meio, mas porque o homem, por si mesmo, é objeto indireto da investigação geográfica, confere expressão fisica à área com suas moradias, seu lugar de trabalho, mercados, campos e vias de comunicação. A geografia cultural se interessa, portanto, pelas obras humanas que se inscrevem na superficie terrestre e imprimem uma expressão característica.

Na França, La Blache, influenciado pelo possibilismo geográfico, considerou nos estudos acerca da paisagem "as possibilidades" de transformação do homem sobre o meio ambiente, porém, reforçou que o mesmo também é influenciado pela natureza. Nesse contexto, surgiu a paisagem natural modificada pela ação humana, ou seja, não houve o rompimento com o viés naturalista no estudo da paisagem, ainda que fosse exaltada a ação humana sobre a mesma. Considerando estas reflexões Guelke (1982, p. 222) nos diz

\section{[...] A paisagem cultural, como um registro da} atividade humana sobre a Terra, propicia um guia inestimável para os valores das pessoas que a elaboraram. Esse registro é mais valioso do que questionários ou respostas subjetivas fornecidas porque ele é um registro de ação, não simplesmente de intenção. Ele espelha as prioridades políticas, econômicas e sociais das sociedades que o criou, indo além da retórica política e constitucional. A idéia de Vidal de La Blache, de que uma paisagem é uma medalha inserida na imagem do povo que a criou, ainda atualmente é válida.

Dessa maneira, a Geografia Cultural Francesa, ao passar por uma renovação a partir da década de 1970, considerou a importância dos sentidos e do corpo na interpretação da paisagem. Destaca que o sentido de maior evidência é a visão ou o olhar do indivíduo. Vale ressaltar que essa perspectiva de compreensão da paisagem, deixou de ter caráter funcionalista ligado à produção agrícola, ou de estar atrelada às funções dessa categoria do espaço no passado. Concordante com essas ideias, Claval (2007, p. 160) reforça

Novas perspectivas apareceram no dominio dos estudos sobre a paisagem no final dos anos setenta. A paisagem cessou de ser concebida como um dado objetivo. O enfoque foi, a partir de então, colocado na dialética entre a dimensão objetiva e a dimensão subjetiva do olhar e sobre a relação entre a paisagem como marca da cultura e a paisagem como matriz da cultura. [...] Mas a paisagem é também um gênero de pintura. As questões essenciais que são colocadas nesse domínio são as seguintes: I-Qual é o sentido da paisagem nas sociedades onde ela se tornou um tema da pintura? II- Por que a pintura da paisagem apareceu mais cedo e 
unicamente nas áreas das civilizações européias (desde o século XV)? III - Qual o equivalente do sentido estético da paisagem nas culturas em que não existe a arte da pintura da paisagem ou a arte dos jardins?

Nos Estados Unidos, Sauer investigou a diversidade das paisagens na Terra como resultado da relação das culturas com o lugar de vivência e com o meio ambiente. $\mathrm{O}$ autor também considera a relevância da paisagem natural e da transformação dessa natureza pelo homem, originando a paisagem cultural. Cosgrove; Jackson (2007, p. 136) salienta que

A paisagem permanece um terreno fértil para os geógrafos culturais, mas Carl Sauer e seus seguidores da Escola de Berkeley não são mais seus únicos interlocutores. Sauer e seus discípulos, investigando o mundo rural e arcaico, concentravam-se em artefatos físicos especificos (as cabanas de madeira, as cercas dividindo territórios). Apesar de raramente o explicitarem, seus trabalhos baseavam-se no seguinte pressuposto etnológico: áreas geográficas distintas (paisagens) podem ser identificadas e descritas através do mapeamento dos elementos visiveis da cultura material produzida pelos grupos culturais unitários.

Os estudos de Sauer envolviam, também, as paisagens diversificadas, comparando-as e ressaltando suas diferenças, considerando a evolução histórica das culturas manifestadas nessas paisagens, bem como o tempo e o local onde os grupos expressam suas características culturais.

Com esse propósito, a Geografia, contempla o estudo dos aspectos que compõem a paisagem, desde a determinação e precisão do local onde a mesma se encontra até a explicação de sua configuração, resultado da soma dos elementos naturais e culturais. A paisagem é, então, fruto da natureza e da luta humana para se adequar às dificuldades imposta pelo meio ambiente e pelos outros homens. A cultura se afirma na paisagem ao materializar os símbolos característicos de uma identidade cultural específica. Corrêa; Rosendahl (2004, p.10) nos advertem que
Considerada como um texto, a paisagem é vista desempenhando importante papel na sociedade: por meio dela o sistema social é comunicado, reproduzido, experimentado e explorado. [...] A paisagem é interpretada diferentemente pelos grupos locais e de fora, e evidenciar como essas interpretações foram construidas constitui importante papel para o geógrafo cultural. A retórica da paisagem coloca em questão os processos pelos quais ela, enquanto um texto, é lida, seja pelo impacto objetivo de suas formas, seja por meio de figuras de linguagem nelas impressas. A paisagem tem uma textualidade e uma intertextualidade.

Com a superação da Geografia Clássica, responsável pela valorização da paisagem natural e sua transformação em paisagem cultural, emerge a Nova Geografia enfatizando as técnicas quantitativas e as tecnologias. Frente ao estudo da paisagem, enfatiza-se que esse período da historiografia do pensamento geográfico não representou mudanças expressivas, mantendo a influência da Geografia Tradicional no conceito em questão. Bezzi (2004, p. 14) reforça "No entanto, o uso excessivo de técnicas quantitativas pela Nova Geografia comprometeu o caráter antropocêntrico das pesquisas geográficas e não foram suficientes para explicar a realidade, bem como não há preocupação com problemas sociais".

No entanto a Geografia Crítica atribuiu à noção de paisagem um olhar social característico dessa escola geográfica utilizando as ferramentas teórico-metodológicas do marxismo. Desse modo, o humanismo retorna à Geografia e os aspectos cultural, social e individual da paisagem ganham relevância. Duncan (2004, p. 121) destaca que esse olhar social instigou os geógrafos culturais a compreenderem

[...] o papel ativo que as paisagens desempenham nos sistemas culturais. Devemos focalizar nossa atenção tanto sobre a significação quanto sobre a retórica da paisagem. Devemos também investigar o papel da textualidade e da intertextualidade no debate sobre discursos e na disputa sobre o significado das paisagens. Esses debates e disputas, que 
podem se fundamentar em interesses materiais reais, frequentemente desempenham um papel significativo no processo político.

Pode-se afirmar, então, que a vertente crítica do pensamento geográfico considerou a paisagem como fruto dos acontecimentos históricos responsáveis por sua evolução, seguindo as diretrizes do método dialético e da compreensão de que as formas influenciadas pela presença de determinada cultura moldam essa paisagem, manifestando a relação entre o homem e o meio.

Santos (2002, p. 25) comenta que a paisagem é construída por tudo o que é visível combinado com os movimentos e os sons imersos na mesma. Para o autor, existe a paisagem natural, porém, ela é quase inexistente na atualidade, considerando que grande parte delas apresenta as marcas da ação humana.

Para a verificação da presença de uma determinada cultura, considera-se importante verificar a paisagem urbana do local a ser analisado, pois o espaço urbano possibilita a leitura dessa paisagem. Segundo Corrêa (2007, p. 179-180) deve-se considerar que

A paisagem constitui parte do conjunto compartilhado de idéias, memórias e sentimentos que une uma população. [...] A paisagem urbana, por outro lado, ao ser um meio de comunicação da identidade social e étnica, torna-se um relevante elemento do processo de reprodução social, em virtude de ser um repositório de símbolos de classe social e de herança étnica. A paisagem residencial está, em realidade, impregnada de sentimentos $e$ simbolismos.

Salienta-se, também, uma estreita relação entre paisagem e técnica, ou seja, a formação da paisagem cultural envolve a elaboração e utilização de instrumentos característicos de um grupo que permitem a transformação da paisagem natural em uma paisagem humanizada e, portanto, culturalmente marcada. As ferramentas criadas por meio da elaboração das técnicas servem como uma extensão do homem e, com a larga utilização desses instrumentos, são, também, peças ligadas à natureza. De acordo com Claval (2007, p. 161) a Geografia Cultural francesa a partir da década de 1980 e início da de 90, ressalta que era fundamental

[...] estudar os instrumentos usados pelos seres humanos para aprender as realidades do meio ambiente ou do meio social. No começo dos anos oitenta, esse tipo de pesquisa se desenvolveu rapidamente nas universidades da parte oriental da França, em Grenoble, por exemplo, ou nas universidades da Suiça de língua francesa, em Genève ou Lausanne, por exemplo.

Essas reflexões demonstram que a identidade e outras noções ligadas à cultura, enfatizam que a paisagem não permanece estática, mas se modifica estrutural e funcionalmente com o decorrer do tempo. Santos (1997) reforça tal afirmação quando identifica as formas viúvas da paisagem como aquelas envelhecidas, aguardando uma revitalização e, as formas virgens, configuradas para a realização de novas funções.

Nesse sentido, evidencia-se a complexidade fornecida ao conceito de paisagem pela Geografia Crítica, a qual valoriza essa categoria de análise do espaço ao abarcar todos os elementos da paisagem e, não apenas, os atributos culturais e naturais. A materialidade e a imaterialidade da paisagem têm importância nas pesquisas direcionadas ao olhar crítico da Geografia, entendendo essa categoria como um conjunto único e capaz de expressar todas as marcas da ação humana. Cosgrove; Jackson (2007, p.137) reforçam essa afirmação, pois

Ao se reconstruir os conceitos de paisagem e de cultura com novas referências conceituais, os estudos recentes de geografia cultural enfatizam o caráter de construção cultural sofisticada do próprio conceito de paisagem. [...] o conceito de paisagem é ele próprio, um modo especial de compor, estruturar e dar significado a um mundo externo, cuja história tem que ser entendida em relação à apropriação material da terra. Assim, as qualidades simbólicas da paisagem, que produzem e sustentam seu significado social, tornaram-se objeto de pesquisa, ampliando as fontes disponíveis para a geografia cultural. 
O estudo da paisagem enfatiza o caráter humanístico das investigações geográficas, antes sustentado pela observação e descrição dos caracteres naturais. A relevância de uma paisagem marcada também, pela imaterialidade, conferiu maior subjetividade ao conceito de paisagem, ou seja, ela é, portanto, o resultado da interação entre a materialidade das formas e o sentimento que desperta nas pessoas que a observam e a vivenciam no cotidiano de suas vidas.

Nessa perspectiva, a Geografia Humanística evidencia a metáfora da paisagem como texto que de acordo com Cosgrove; Jackson (2000, p.18) deve "[...] ser lido e interpretado como documento social", podendo ser compreendida segundo a descrição dos símbolos presentes na mesma. Os primeiros trabalhos inseridos nessa perspectiva de estudo, vinculavam atributos muito superficiais, ligados à estética da paisagem. Outras investigações mais aprofundadas, atreladas à interpretação dessa categoria do espaço, não pertenciam à ciência geográfica, mas impulsionaram as pesquisas acerca dessa temática. Cosgrove; Jackson (2007, p. 137) apontam que

O conceito de paisagem como configuração de símbolos e signos leva a metodologias mais interpretativas do que morfológicas. Entre as metodologias interpretativas mais favorecidas estão aquelas da lingüística e da semiótica, associadas ao avanço do pós-guerra. A linha interpretativa dentro da geografia cultural recente desenvolve a metáfora da paisagem como "texto", a ser lido e interpretado como documento social.

Frente a essa possibilidade de leitura da paisagem como um texto, Mikesell (2000, p. 94) critica, destacando que

O estudo da paisagem também possui um conjunto de problemas não resolvidos. A passagem da descrição morfológica para a interpretação simbólica pode ser considerada um prenúncio de progresso. Todavia, a idéia em voga de que as paisagens podem ser "lidas" como "textos" causa perplexidade. $O$ unico limite para a quantidade de leituras plausíveis é o número de leitores potenciais.
E qualquer paisagem torna-se um composto "textual" de múltiplas camadas. Mudando da analogia textual para outra, mais antiga, talvez fosse justo dizer que o estudo da paisagem se inspirou numa variante do princípio cartesiano: vejo, logo isto existe. Mas se você não vê o que vejo, como podemos concordar sobre o que "isto" significa?

Pode-se dizer, então, que o estudo da paisagem pode ser realizado através do método iconográfico, que contempla a análise dos símbolos e signos representativos de uma determina cultura. Mais uma vez se resgata Cosgrove; Jackson (2000, p. 23) quando os autores dizem que

As sociedades mais primitivas, com menos comércio, que foram estudadas pela geografia cultural tradicional, tinham códigos simbólicos mais estáveis que os das sociedades contemporâneas. $O$ mundo pós-moderno - marcado pela liberdade de atribuir significados e pela intertextualidade, com a qual invertemos signos e símbolos para reciclá-los em contextos diversos e, dessa forma, transformar sua referência - enfatiza a superfície e, não a profundidade (Youngs, 1985; Daniels e Cosgrove, 1987). Consequentemente, poucos são os métodos iconográficos ou de diagnóstico que recorrem à "interpretação em profundidade" para estudar as paisagens contemporâneas.

Nessa linha de raciocínio, Claval (2007, p. 152) nos diz que "Iconografia são representações por meio de símbolos, base de todas as suas interpretações do mundo político". Esse sistema simbólico é aplicado, segundo Cosgrove; Jackson (2007, p.139) “[...] não só no caso mais óbvio de mapas topográficos (HARLEY, 1983), mas também numa coleção de estudos sobre a paisagem, em sentido mais amplo [...]". Ainda se tratando sobre o estudo da paisagem, Cosgrove; Jackson (2000, p.18), afirmam que

Se a paisagem passa a ser considerada uma imagem cultural, "um meio pictórico de repre- 
sentar ou simbolizar tudo o que circunda o ser humano, então pode ser estudada através de vários meios e superficies: por intermédio da pintura sobre a tela, da escrita sobre o papel, das imagens gravadas em filme, e mesmo da terra, da pedra, da água e da vegetação sobre o solo".

A valorização dos símbolos refere-se, também, à construção de paisagens religiosas, ou seja, aquelas que, através da experiência vinculada à religião, se estruturam e criam formas e funções ligadas à religiosidade de um grupo cultural. Nesse contexto, a Geografia Cultural deve permitir a compreensão da produção dessa paisagem, atrelada à vivência religiosa nesse lugar sagrado e à manifestação simbólica dessa religião nessa categoria do espaço. Rosendahl (2007, p. 214) complementa

Embora lugares sagrados possam resultar de processos de sacralização, as paisagens são criadas por determinados grupos religiosos, no desejo de reproduzir sua própria visão de mundo. Bonnemaison (1981) nos leva a reconhecer que os simbolos ganham mais força e realce quando se encarnam em lugares religiosos. O espaço é percebido como uma trama geossimbólica de comunicação partilhada por todos. A paisagem é uma estrutura visivel, na qual a mensagem que nela se escreve em termos geossimbólicos reflete no peso do sonho, das crenças dos homens e de sua busca de significação.

A paisagem cultural é, constituída, nesse sentido, pelos códigos da cultura que a formou, sendo a expressão da identidade desse grupo por meio de suas formas visíveis e dos seus hábitos, atribuindo significado a essa categoria do espaço.

A representatividade cultural da paisagem não se refere, apenas, aos aspectos materializados, mas a tudo que faz parte dela, sejam os aromas, sons, as pessoas, animais e objetos que "preenchem" essa paisagem de vida, cores e peculiaridades. Essa categoria do espaço exige, não apenas uma observação superficial, mas uma leitura aguçada do significado das funções que exerce, das formas que apresenta e dos sentimentos que desperta nos indivíduos que vivenciam o cotidiano da mesma.

A cultura torna relevante o sistema simbólico presente na paisagem e, não somente sua função utilitarista, considerando os valores, ideologias e crenças que nortearam e ainda norteiam o grupo cultural formador da mesma. Assim, cada cultura imprime na paisagem e descreve a mesma de acordo com a compreensão que tem do mundo e da vida, ou segundo a forma como seus integrantes se comunicam entre si e com outras culturas. A esse respeito Duncan (2004, p. 95) enfatiza

As descrições não são reflexos espelhados; são necessariamente construídas dentro dos limites da linguagem e das estruturas intelectuais daqueles que descrevem. Tal linguagem não é uma série de palavras que tem correspondência exata com a realidade "exterior". Ela se baseia em discursos que são significados partilhados constituidos socialmente, em ideologias, em séries de suposições do "senso comum". As mesmas palavras podem ter diferentes significados em diferentes discursos. As descrições podem ter significado somente em um sentido contextualizado.

Nesse contexto, os homens, movidos por vontades e ideais semelhantes, estruturam, juntamente com outros homens, paisagens semelhantes, porém, são as diferenciações de pequenos detalhes dos instrumentos e outros objetos que eles produzem, bem como, das maneiras como orientam suas condutas no espaço que irão construir as particularidades formadoras de várias culturas.

Por conseguinte, verifica-se que a paisagem é objeto de estudo de muitas ciências, como jornalistas, historiadores, sociólogos, antropólogos e arquitetos entre outros. A Geografia Cultural insere nessa análise, a contribuição dessa categoria do espaço para a dinâmica do processo social. Duncan (2004, p. 90) destaca que

Embora as paisagens tenham sido tradicionalmente reconhecidas como reflexos da cultura dentro da qual foram construidas, 
ou como uma espécie de indícios produzindo "rastros" de artefatos relacionados a acontecimentos do passado, especialmente de difusão, só raramente elas foram reconhecidas como elementos constituintes na evolução dos processos sociopolíticos de reprodução e transformação cultural. [...] Os geógrafos culturais, que ironicamente pouco se interessaram pela cultura, voltaram sua atenção quase que exclusivamente para os artefatos. Através dos anos, inúmeros artigos em periódicos se dedicaram ao tópico da distribuição regional - e ocasionalmente, da difusão - de artefatos tais como tipos casas, de celeiros, de cercas, ou "conjuntos" de paisagens, dos quais se dizia que revelavam regiões culturais ou focos culturais.

Nesta perspectiva, a paisagem cultural deve ser compreendida como a relação entre a evolução de uma cultura no tempo e a transformação que ela provoca na paisagem natural. Essa paisagem cultural se afirmará desse modo, através das singularidades dos símbolos impressos na mesma, marcando a presença de determinado grupo cultural.

\section{AIMPORTÂNCIA DOS CÓDIGOS CULTURAIS: A MATERIALIDADE E IMATERIALIDADE DA CULTURA MANIFESTADA NA PAISAGEM}

Uma cultura pode se manifestar na paisagem por meio dos códigos culturais que se configuram como um sistema de símbolos que permitem a visualização dessa cultura. Esses códigos possibilitam, também, a transmissão, das características culturais de determinado grupo através das gerações. Wagner; Mikesell (2007, p. 28) reforçam essa afirmação definindo que "A cultura resulta da capacidade de os seres humanos se comunicarem entre si por meio de símbolos".

Neste contexto, Cosgrove (2007, p.103) afirma que

Os seres humanos experienciam e transformam o mundo natural em um mundo humano, através de seu engajamento direto enquanto seres pensantes, com sua realidade sensorial e material. A produção e reprodução da vida material são, necessariamente, uma arte coletiva, mediada na consciência e sustentada através de códigos de comunicação. Esta última é produção simbólica. Tais códigos incluem não apenas a linguagem em seu sentido formal, mas também o gesto, o vestuário, a conduta pessoal e social, a música, pintura, a dança, o ritual, a cerimônia e as construções. Mesmo essa lista não esgota a série de produções simbólicas através das quais mantemos o nosso mundo vivido, porque toda atividade humana é, ao mesmo tempo, material e simbólica, produção e comunicação. Essa apropriação simbólica do mundo produz estilos de vida (genres de vie) distintos e paisagens distintas, que são histórica e geograficamente especificos. A tarefa da geografia cultural é apreender e compreender essa dimensão da interação humana com a natureza e seu papel na ordenação do espaço.

Pode-se afirmar que os atributos culturais se expressam nas paisagens através do estilo arquitetônico das casas, trajes típicos, arte, gastronomia, religião, músicas, danças e festividades, entre outros elementos. Brum Neto (2007, p. 38) destaca que "Além desses, existem outros códigos que, embora não sejam visíveis, também são responsáveis pela materialização da cultura no espaço, como aportes culturais, com destaque para os valores, ideologias e convenções".

Convém enfatizar que as cidades expressam a manifestação das particularidades culturais de um grupo, apresentando as transformações simbólicas de uma cultura através da temporalidade. Antigas formas são destruídas para que as novas sejam construídas, velhas funções se modificam para que as antigas formas empreguem novos desempenhos frente à evolução da sociedade. Essas alterações não se limitam, apenas, à forma e à função, mas ao significado desses símbolos. Cita-se como exemplo, a representatividade da igreja para a Idade Média, ou dos grandes prédios para a pós-modernidade refletem essa idéia. Corrêa (2007, p. 177 - 178) aponta que

É, em parte, por meio das formas simbólicas que a cidade expressa uma dada cultura e 
realiza o seu papel de transformação cultural, tanto em sua hinterlândia como em seu próprio espaço interno, tanto no passado como no presente e visando ao futuro. [...] A temática em tela, numa perspectiva espacial, situa-se na vaga fronteira entre a geografia econômica e a geografia cultural. Do ponto de vista da geografia cultural, é interessante reconhecer a identidade desses centros, assim como a identidade com eles por parte dos diversos grupos sociais, insiders e outsiders, conforme aponta Relph (1976). É relevante, por outro lado, considerar as condições de gênese das formas simbólicas e de suas articulações com outras atividades.

Dessa forma, considera-se que todo elemento cultural que permite sua visualização na paisagem é um código cultural material e aquele que não possibilita tal visualização constitui-se em um código cultural imaterial. Nesse sentido, destacam-se os principais códigos culturais materiais, entre eles, o estilo das casas, a música, religião, festas e vestuário, entre outros, e os imateriais, caracterizados segundo três elementos principais: os valores, as ideologias e as convenções (CLAVAL, 1999).

Iniciamos nossa reflexão pelos códigos culturais materiais e, entre eles, destaca-se o estilo arquitetônico das casas. Este permite visualizar os aspectos físicos e os feitios característicos que comprovam a utilidade prática da residência, como, por exemplo, a estruturação dos aposentos e a configuração da área que rodeia e organiza o espaço dessa habitação. Assim, enfatiza-se a importante relação entre a cultura manifestada na paisagem pelas formas específicas expressas pelo estilo da casa.

A música é outro código e se caracteriza por ser um importante elemento cultural, pois exalta o que tem de significado para uma cultura, recorrendo ao passado e aos valores da história de um grupo social. A música reporta o ouvinte para as raízes de sua cultura. Admite-se que as canções expressam uma carga simbólica representativa. Nesse sentido, a música pode ser um veículo de manifestação da fé em rituais religiosos, com cantos que declamam uma prece representativa das experiências de vida e da imaginação dos indivíduos que, simbolicamente, através deste código, expressam a religiosidade como marca característica da cultura a qual pertencem.

A religião também é um código cultural que manifesta as crenças de um determinado grupo social. Esse código cultural apresenta atributos materiais e imateriais, ou seja, pode ser visível na paisagem através de sua materialidade por meio das igrejas, grutas, capitéis, monumentos sacros, festividades religiosas (procissões), entre outros. Ou, através da imaterialidade ligada aos valores que orientam a ideologia de determinada cultura. Dessa forma, salienta-se que é a religião e seus ritos sacros que agregam os indivíduos pertencentes a um grupo social. Aponta-se, nessa perspectiva, a importância dos estudos de Zeny Rosendahl, uma das referências acerca da Geografia da Religião brasileira.

No final da década de 1990, a perspectiva cultural ligada à temática da religião, enfocou o sagrado e o profano como dois pontos centrais a serem entendidos pelo viés cultural. Nessa perspectiva, Duncan (2000, p. 90) salienta que

A religião, da mesma forma que a linguagem,
é um sistema de comunicação e um mecanis-
mo de promover a integração, quando não o
conflito. Sua distribuição gera questões de
origem, propagação e fronteiras. A religião
é um sistema de valores que tanto incentiva
como inibe a atividade humana, por isso,
merece mais atenção dos especialistas da
geografia humana.

O sagrado se sustenta pela produção de bens simbólicos os quais revelam a devoção. A este respeito e considerando a religiosidade de uma cultura, Rosendahl (2007, p. 189-190) acrescenta que

A diferenciação entre um bem simbólico e um bem não simbólico está na própria natureza de seu significado. A natureza do bem simbólico reflete duas realidades: a mercadoria e o significado, isto é, o valor cultural e o valor mercantil do bem. Poderíamos dizer que os bens simbólicos são mercadorias que possuem valor de uso e que, em determinado contexto cultural, passam a ter associado o valor simbólico.[...] É certo que o sistema religioso é formado por um conjunto de símbolos sagra- 
dos ordenados entre si, numa ordem conhecida pelos seus adeptos", aponta Geertz (1989; 143). O bem religioso está profundamente comprometido com o sagrado e, como tal, é marcado por signos e significados; mas deve ser reconhecido também como fornecedor de regras e sentidos aos grupos religiosos. É o bem simbólico que dá sentido e significado às práticas religiosas de diferentes grupos.

Dessa forma, a comunidade constrói uma hierópolis. Este conceito segundo Rosendahl (2007, p. 206) significa que "[...] todos aqueles lugares considerados sagrados por uma dada população local, regional ou nacional". São, portanto, locais povoados que, durante todo o ano ou por um período anual, se dedicam a atividades religiosas que visam, ainda, a comercialização de artigos vinculados à religião.

Neste contexto, a religião para determinadas culturas, é o código de maior expressividade. Muitos povos são identificados no espaço devido os elementos que representam a religiosidade do mesmo. Isso ocorre porque a religião se imprime na paisagem de uma maneira duradoura e abrangente e, por isso, se constitui em um dos atributos culturais mais relevantes quando se estuda grupos sociais. Também para Rosendahl (2007, p. 216) "Interpretar as paisagens religiosas significa reconhecer crenças e identidades culturais de seus habitantes".

As festividades (entre elas, as religiosas) também se constituem em códigos culturais, pois são expressões próprias de um povo que manifestam o louvor por alguma divindade religiosa, entidades espirituais ou a comemoração pelos resultados ligados à atividade agrícola, entre outras razões. Esse código cultural envolve outros elementos característicos da cultura de um grupo social, como a música, a dança, os trajes típicos, a gastronomia e a religião.

Nessa perspectiva, as festas religiosas com procissões, música, quermesses e parques, representam a expressão da religião na paisagem em um determinado período do ano. São comemorações vinculadas à devoção de santos que, por ter como motivo central, a crença de uma cultura, é permitida e comemorada por todos que pertencem à esse grupo. Rosendahl (2007, p. 213) destaca que "[...] a festa religiosa urbana, ao contrário dos eventos religiosos nos centros rurais afastados, adquire um sentido mais modesto e de curto período de tempo, mas mesmo assim representa uma função de renovação espiritual".

Outro código cultural significativo é o vestuário característico de uma cultura. Ele expressa a origem do local onde um grupo específico se consolidou, manifestando os aspectos físicos desse espaço e a utilidade dessa vestimenta no cotidiano dessa cultura. Os trajes típicos pertencem às tradições de um povo e, por isso, exaltam as crenças, conhecimentos e costumes desse grupo, carregando, portanto, uma simbologia própria, representado pelas cores e modelos característicos. Embora não sejam usados no cotidiano, são resgatados nas festas tradicionais e nos desfiles típicos.

Enfatiza-se nesse estudo, a importância da linguagem como código cultural capaz de perpetuar as características de uma cultura através das gerações, ao descrever oralmente ou através da escrita, a história de luta desse grupo, o significado do estilo das casas, gastronomia, vestimentas, festas e músicas desse povo, além de afirmar a importância da manutenção de suas crenças, valores e ideologias. Para Wagner; Mikesell (2007, p.29)

A língua, como meio essencial da comunicação humana, é obviamente um componente crucial de qualquer cultura. A influência exata da língua sobre a cultura tem sido estimada, mas nunca estabelecida claramente. Seja como for, a lingua, por sua vez, é fortemente afetada por outros aspectos de uma cultura. Quaisquer que possam ser estas inter-relações, a linguagem de uma comunidade é uma de suas características distintivas. Uma cultura pode, certamente, abranger ou sobrepor diversos grupos lingüisticos diferentes, desde que seja mantido algum tipo de equivalência entre os sistemas simbólicos coexistentes; da mesma forma, um grupo lingüístico pode ser dividido entre diversas culturas diferentes.

Considera-se então que a linguagem é tanto um código cultural material, quanto imaterial, pois se expressa visualmente através da escrita e, portanto, permanece por mais tempo na cultura de um povo, além de ser invi- 
sível através da oralidade, porém, com grande poder de transmissão mesmo que corra o risco de não se perpetuar por muito tempo e dependa muito da valorização cultural desse grupo. Para Cosgrove (2000, p. 39)

A comunicação é o alicerce da intersubjetividade, ou seja, os valores e crenças compartilhados constituem a imaginação coletiva e definem a cultura não-material. A linguagem é o modo primário da comunicação humana, constituidora da própria individualidade daqueles que a utilizam. Por essa razão, os geógrafos culturais interessados na questão do significado do mundo têm-se dedicado cada vez mais ao papel simbólico da linguagem em nossas relações com o mundo natural, a ponto de alguns deles considerarem as paisagens culturais como textos, construídos de acordo com regras lingüísticas.

De acordo com Mikesell (2000, p. 90) "Na maior parte do mundo, a pesquisa cultural-geográfica traz implícito o conhecimento do isolamento ou da mistura de línguas e dialetos". Destaca-se, por conseguinte, a importância de se considerar, também, as gírias, os ditos populares, os apelidos e a linguagem expressa pelo corpo como parte característica de uma cultura, evidenciando que esse código cultural se manifesta, portanto, de forma espontânea e, também, através da instrução escolar por meio da alfabetização. Mikesell (2000, p. 29) enfatiza que

\section{[...] Exclamações, gestos, expressões faciais} etc. também são linguagens; de outro modo, pinturas, emblemas e tudo o que é regularmente reconhecido como "significando algo" também são linguagens. Finalmente, objetos e comportamentos de todos os tipos entram no processo de comunicação. A cultura atribui significado a tudo, desde sons vocais deliberadamente articulados até seres, objetos e lugares.

Tratando, ainda, a respeito dos códigos culturais imateriais, enfatiza-se, que de acordo com Claval (1999, p. 45), que os mesmos podem ser caracterizados segundo três elementos principais: os valores, as ideologias e as convenções.
Os valores se referem às convicções íntimas e princípios abstratos de conduta, geralmente influenciados pela religião e pela metafísica. As convenções são enraizadas no cerne cultural de um povo, direcionando questões referentes à honra, autoridade e responsabilidade. As ideologias, por sua vez, são estruturações leigas, sem vinculação religiosa e baseada na razão que norteiam a história e o ordenamento social de um grupo cultural. Com relação ao papel da ideologia no imaginário cultural, Cosgrove (2000, p. 48) recorre à Ricoeur, afirmando que

A ideologia oferece mitos e simbolos fundamentais que alicerçam as instituições e as ações coletivas através do ritual. A cultura oficial dos Estados Unidos expressa sua origem histórica na memória da Declaração da Independência de 1776, celebrada nos rituais anuais do dia 4 de julho. E expressa sua origem geográfica através das estrelas de sua bandeira denominada "Old Glory". [...] As nações, como todos os outros grupos, usam o “imaginário social como memória ideológica de atos fundamentais sagrados [...] para integrar e legitimar a ordem social" (Kearney: 1991, 158). A expressão geográfica de tais atos é de interesse evidente para os geógrafos culturais. [...] Sem a força conservadora da ideologia, as utopias podem se tornar agentes de mudança brutalmente destrutivas, a ponto de apagarem culturas inteiras e suas paisagens.

Dessa forma, a ideologia mostra-se conservadora e ao ser vinculada ao sentimento de superioridade e apego extremo ao lugar, pode gerar manifestações de preconceito e extinção de grupos culturais considerados "estranhos" ou diferentes. Cita-se como exemplo o caso da busca pela eliminação do povo judeu da Alemanha promovido pelo Nazismo. A ideologia alemã de amor a terra e de superioridade racial, mostrou o lado perverso desse elemento cultural que, desvinculada da utopia, produziu nacionalismos conservadores marcados pelas lutas étnico-culturais.

A transferência de costumes, hábitos e, também, de modelos de conduta reflete, portanto, uma 
transformação nos códigos culturais originais de um grupo cultural específico, indicando a evolução do sistema simbólico característico de uma cultura, modificado, portanto, para se adaptar a uma nova realidade.

Portanto, a importância dos códigos culturais se firma através da possibilidade de um grupo exaltar sua cultura na paisagem através do compartilhamento dos mesmos símbolos, que os identificarão perante os outros povos através das diferenças culturais. Assim, cada cultura tem seu sistema simbólico específico de representação, porém, essas características não serão eternas, mas irão evoluir no contato com outros grupos e com outras realidades.

\section{CONSIDERAÇÕES FINAIS}

Como uma tradição científica herdada da modernidade, os conceitos são, geralmente, estudados separadamente com a finalidade de apreender todas as características vinculadas aos mesmos para, posteriormente, serem realizadas as relações entre as diferentes noções. No entanto, nem sempre essas vinculações essenciais são feitas, comprometendo, nesse sentido, a compreensão completa desses aportes conceituais. Desse modo, ressalta-se que os conceitos de paisagem cultural e códigos culturais são inseparáveis.

O estudo da paisagem pelo viés da cultura destaca o sistema simbólico de determinado grupo social caracterizado por atributos ou elementos materiais e imateriais, conhecidos na Geografia Cultural como códigos culturais. Estes, como salientado no artigo, podem ser visíveis ou invisíveis na paisagem, atribuindo à mesma, seu caráter cultural.

As peculiaridades inerentes à cultura a tornam instigante e foco de realização de estudos aprofundados sobre suas características, as quais permitem distinções quanto às similaridades e diferenças socioespaciais. A Geografia Cultural consolidada na valorização da materialidade e imaterialidade da cultura enfatiza os aportes responsáveis pelo entendimento dessa noção, mediante a significação dos códigos culturais para um determinado grupo social e para sua identificação.

Neste contexto, deve-se compreender a paisagem, não somente, através de sua materialidade, mas considerar sua imaterialidade. Além da arquitetura, da música, das festividades, das vestimentas, da gastronomia, da linguagem, das danças, entre outros códigos culturais visíveis, as normas, as crenças, os valores e as ideologias também produzem a paisagem porque orientam a conduta dos indivíduos pertencentes a uma cultura, norteando a produção do "visível" representativo desse grupo.

Por conseguinte, os estudos culturais, especificamente, os relacionados aos códigos representativos de uma cultura, contribuem para a compreensão dos aspectos sociais, simbólicos e sua manifestação na paisagem e permitem realizar levantamentos do patrimônio cultural, fornecendo subsídios para ações que promovam essas potencialidades culturais.

\section{REFERÊNCIAS}

BEZZI, M. Região: uma (re)visão historiográfica - da gênese aos novos paradigmas. Santa Maria: UFSM, 2004.

BRUM NETO, H. Região Cultural: a construção de identidades culturais no Rio Grande do Sul e sua manifestação na paisagem gaúcha. 2007, 319 f. Dissertação de Mestrado (Mestrado em Geografia) - Universidade Federal de Santa Maria, Santa Maria, 2006.

CLAVAL, Paul. A Contribuição Francesa ao Desenvolvimento da Abordagem Cultural na Geografia. In: CORREA, R. L.; ROSENDAHL, Zeny (Org.). Introdução à Geografia Cultural. 2. ed. Rio de Janeiro: Bertrand Brasil, 2007. p. 147-166.

. A Paisagem dos Geógrafos. In: CORRÊA, R. L.; ROSENDAHL, Zeny (Org.). Paisagens, Textos e Identidade. Rio de Janeiro: UERJ, 2004. p. 13-75. (Geografia Cultural)

A Geografia Cultural. Tradução de Luíz Fugazzola Pimenta e Margareth Afeche Pimenta. Florianópolis: UFSC, 1999. 
CORRÊA, R. L.. A Geografia Cultural e o Urbano. In: CORREAA, R. L.; ROSENDAHL, Zeny (Org.). Introdução à Geografia Cultural. 2. ed. Rio de Janeiro: Bertrand Brasil, 2007. p. 167-186.

ROSENDAHL, Zeny, Paisagem, Textos e Identidade: Uma apresentação. In: CORRÊA, R. L.; ROSENDAHL, Zeny (Org.). Paisagens, Textos e Identidade. Rio de Janeiro: UERJ, 2004. p. 7-13. (Geografia Cultural)

COSGROVE, D. Em Direção a uma Geografia Cultural Radical: Problemas da Teoria. In: CORRÊA, R. L.; ROSENDAHL, Zeny (Org.). Introdução à Geografia Cultural. 2. ed. Rio de Janeiro: Bertrand Brasil, 2007. p. 103-134.

Mundos de Significados: Geografia Cultural e Imaginação. In: CORRÊA, R. L.; ROSENDAHL, Zeny (Org.). Geografia Cultural: Um Século (2). Rio de Janeiro: UERJ, 2000. p. 33-60. (Geografia Cultural)

; JACKSON, P. Novos Rumos da Geografia Cultural. In: CORRÊA, R. L.; ROSENDAHL, Zeny (Org.). Introdução à Geografia Cultural. 2. ed. Rio de Janeiro: Bertrand Brasil, 2007. p. 135-146.

. Novos Rumos da Geografia Cultural. In: CORRÊA, R. L.; ROSENDAHL, Zeny (Org.). Geografia Cultural: Um Século (2). Rio de Janeiro: Ed. da UERJ, 2000, p.15-32. (Geografia Cultural)

DUNCAN, J. A Paisagem como Sistema de Criação de Signos. In: CORREAA, R. L.; ROSENDAHL, Zeny (Org.). Paisagens, Textos e Identidade. Rio de Janeiro: UERJ, 2004. p. 91-132. (Geografia Cultural)

. Após a Guerra Civil: Reconstruindo a Geografia Cultural como Heterotopia. In: CORRÊA, R. L.; ROSENDAHL, Zeny (Org.). Geografia Cultural: Um Século (2). Rio de Janeiro: UERJ, 2000. p. 61-84. (Geografia Cultural)
GANDY, M. Paisagem, Estéticas e Ideologia. In: CORREAA, R. L.; ROSENDAHL, Zeny. (Orgs). Paisagens, Textos e Identidade. Rio de Janeiro: UERJ, 2004. p. 76-91. (Geografia Cultural)

GUELKE, L. Geografia Regional. In: CHRISTOFOLETTI, A. Perspectivas da Geografia. São Paulo: Difel, 1982. p. $213-224$.

LEITE, M. A. F. Destruição ou Desconstrução? São Paulo: HUCITEC, 1994.

MIKESELL, M. Posfácio: Novos interesses, problemas não resolvidos e tarefas que persistem. In: CORREAA, Roberto Lobato; ROSENDAHL, Zeny (Org.). Geografia Cultural: Um Século (2). Rio de Janeiro: UERJ, 2000. p. 85-108. (Geografia Cultural)

ROSENDAHL, Zeny. Espaço, Cultura e Religião. In: Introdução à Geografia Cultural. Rio de Janeiro: Bertrand Brasil, 2007. p. 147 - 161.

SANTOS, M. Por Uma Geografia Nova. 2. ed. São Paulo: EDUSP, 2002.

. Técnica, Espaço, Tempo - Globalização e Meio Técnico-Científico-Informacional. 3. ed. São Paulo: EDUSP, 1997.

SAUER, Carl. Geografia Cultural. In: CORRÊA, R. L.; ROSENDAHL, Zeny (Org.). Introdução à Geografia Cultural. 2. ed. Rio de Janeiro: Bertrand Brasil, 2007. p. 19-26.

WAGNER, P.; MIKESELL, M. Os Temas da Geografia Cultural. In: CORRÊA, R. L.; ROSENDAHL, Zeny (Org.). Introdução à Geografia Cultural. 2. ed. Rio de Janeiro: Bertrand Brasil, 2007. p. 27-62. 